\title{
ANALISIS KELAYAKAN INVESTASI PENGEMBANGAN USAHA ARTOMORO 2 DI MART DI GENTASARI
}

\author{
Angga Merlinda Septiana \\ Fakultas Ekonomi Universitas Muhammadiyah Purwokerto \\ Akhmad Darmawan \\ Fakultas Ekonomi Universitas Muhammadiyah Purwokerto
}

\begin{abstract}
This research was aimed at knowing whether or not the the ARTOMORO2 Mart was feasible to be established on the market and marketing aspect, technical aspect of production and technology, management and human resources aspect, financial and economic aspect as well as the aspect of law and legality.

The object of this research was an Analysis on the investment Expedience of Business Development of Artomoro2 Mart. The analysis used were leasquare method, market share method, qualitative method or score load, S.W.O.T analysis method, Payback Period,Net present value, Internal Rate of Return, Profitability Index, and S.W.O.T Analysis of legal aspect.

The result of this research showed that based on the market and marketing aspect,ARTOMORO2 Mart was feasible to be established because it was good in the competitive strategy. ARTOMORO2 Mart was also feasible accourding to the technical aspect of production and technology because it applied an advanced technology. The market did not produce commodities due to the fact that market was only selling. Based on the management and human resources aspect, ARTOMORO2 Mart was also feasible to be established because of the calculation of financial aspect showing that the investment was feasible to be established because of the calculation of financial aspect showing that the investment was feasible to be done. Based on the legal aspect analysis, ARTOMORO2 Mart was not feasible yet because it did not have a strong legal agency which was legitimized by the ministry of justice.
\end{abstract}

Keyword : Market and Marketing Aspect, Technical Aspect of Production and Technology, Management and Human Resources and Aapect, Financial and Economic Aapect, Legal Aapect

\section{ABSTRAK}

Penelitian ini bertujuan untuk mengetahui apakah yang ARTOMORO2 Mart adalah layak untuk disebut di pasar dan aspek pemasaran, aspek teknis produksi dan teknologi, aspek manajemen sumber daya manusia, keuangan dan aspek ekonomi serta aspek hukum dan legalitas. Tujuan dari penelitian ini adalah untuk menganalisis kelayakan investasi Pengembangan Bisnis Artomoro2 Mart. Analisis yang digunakan adalah metode leasquare, metode market share, metode kualitatif atau score load, metode analisis S.W.O.T, Payback Period, Net Present Value, Internal Rate of Return, Profitability Index, dan Analisis S.W.O.T dari aspek hukum.

Hasil penelitian ini menunjukkan bahwa berdasarkan aspek pasar dan pemasaran, ARTOMORO2 Mart adalah layak untuk didirikan karena baik dalam strategi kompetitif. ARTOMORO2 Mart juga mengikuti pertumbuhan layak untuk aspek teknis produksi dan teknologi karena menerapkan teknologi canggih. Pasar tidak menghasilkan komoditas karena fakta bahwa pasar hanya menjual. Berdasarkan aspek manajemen sumber daya manusia, ARTOMORO2 Mart juga layak untuk didirikan karena perhitungan aspek keuangan menunjukkan bahwa investasi itu layak untuk didirikan karena perhitungan aspek keuangan menunjukkan bahwa investasi itu layak untuk dilakukan. Berdasarkan analisis aspek hukum, ARTOMORO2 Mart tidak layak karena tidak memiliki badan hukum yang kuat yang dilegitimasi oleh kementerian hukum.

Kata Kunci: Aspek Pasar dan Pemasaran, Aspek Teknis Produksi dan Teknologi, Aspek Manajemen Sumber Daya Manusia, Aspek Keuangan dan Ekonomi, Aspek Hukum. 


\section{PENDAHULUAN}

\section{A. Latar Belakang}

Perkembangan bisnis ritel di era globalisasi ini berkembang begitu pesat, karena seiring dengan meningkatnya kebutuhan masyarakat dunia. Salah satu bisnis ritel yang pertumbuhannya terbilang pesat adalah minimarket. Tren minimarket muncul karena orientasi berbelanja masyarakat berubah. Dulu konsumen dapat dikatakan selalu mengejar harga murah. Sekarang itu tidak cukup kenyamanan dalam berbelanja juga menjadi daya tarik sendiri.

Hal ini yang membuat konsumen memilih berbelanja kebutuhan sehari-hari di minimarket daripada di warung atau toko tradisional lainnya. Di warung atau toko tradisional, konsumen harus menanyakan harga suatu barang. Di minimarket, konsumen dapat melihat, memilih dan menentukan sendiri barang yang akan di beli berdasarkan harga yang tertera. Bahkan pada akhirnya konsumen tidak hanya sekedar membeli barang yang dibutuhkan saja tetapi juga barang yang diinginkan. Perbedaan yang mendasar antara minimarket dengan warung atau toko tradisional bisa dilihat dari pelayanan, bentuk gerai dan tingkat kenyamanan. Dengan demikian institusi bisnis ritel tersebut harus saling berhadapan untuk merebut konsumen dalam satu area perdagangan.

Menurut Salim Murdifin (2010) Investasi berkaitan dengan pengeluaran dana pada saat sekarang dan manfaatnya baru akan diterima dimasa mendatang. Maka investasi berhadapan dengan resiko, setidaknya berkaitan dengan nilai rill yang akan diterima dimasa datang dan resiko mengenai ketidakpastian menerima uang dalam jumlah yang sesuai dengan perkiraan yang akan diterima di masa datang. Kondisi tidak pasti dan berisiko yaitu hasil atau akibat tertentu dari keputusan yang dibuat sekarang yang belum diketahui dengan pasti pada masa yang akan datang. Semakin jauh jarak antara waktu pengambilan keputusan dengan penerimaan manfaatnya dimasa yang akan datang,maka risiko menjadi semakin besar.

Salah satu mininimarket yang menarik bagi penulis adalah minimarket Artomoro. Minimarket ini berdiri pada tahun 2004 dan membuka perluasannya pada tahun 2014. Alasan dilakukan perluasan usaha yaitu karena minimarket Artomoro sebelumnya sudah meraih profit yang cukup besar sehingga mampu membuka perluasan usaha lagi yang diharapkan dapat memberikan keuntungan yanglebih besar lagi. Dalam pendiriannya banyak kendala yang dihadapi mulai dari pengelolaan dana ,bagaimana promosi yang dilakukan agar konsumen tertarik berbelanja di Artomoro2 Mart sehingga dapat mengembalikan modalnya secepat mungkin dan bagaimana mengatasi opini masyarakat yang pro dan kontra dengan pendirian minimarket tersebut mengingat banyak warung kecil dan toko yang ada disekitarnya. Dengan adanya fenomena ini penulis memutuskan memberi judul ANALISIS KELAYAKAN INVESTASI USAHA MINIMARKET ARTOMORO.

\section{Tujuan Penelitian}

a. Untuk mengetahui layak atau tidak ARTOMORO2 Mart untuk di dirikan berdasarkan aspek pasar dan pemasaran,aspek teknis produksi dan teknologi,aspek manajemen dan sumber daya manusia,aspek keuangan dan ekonomi dan aspek hukum dan lesgalitas 


\section{B.Kerangka Pemikiran}

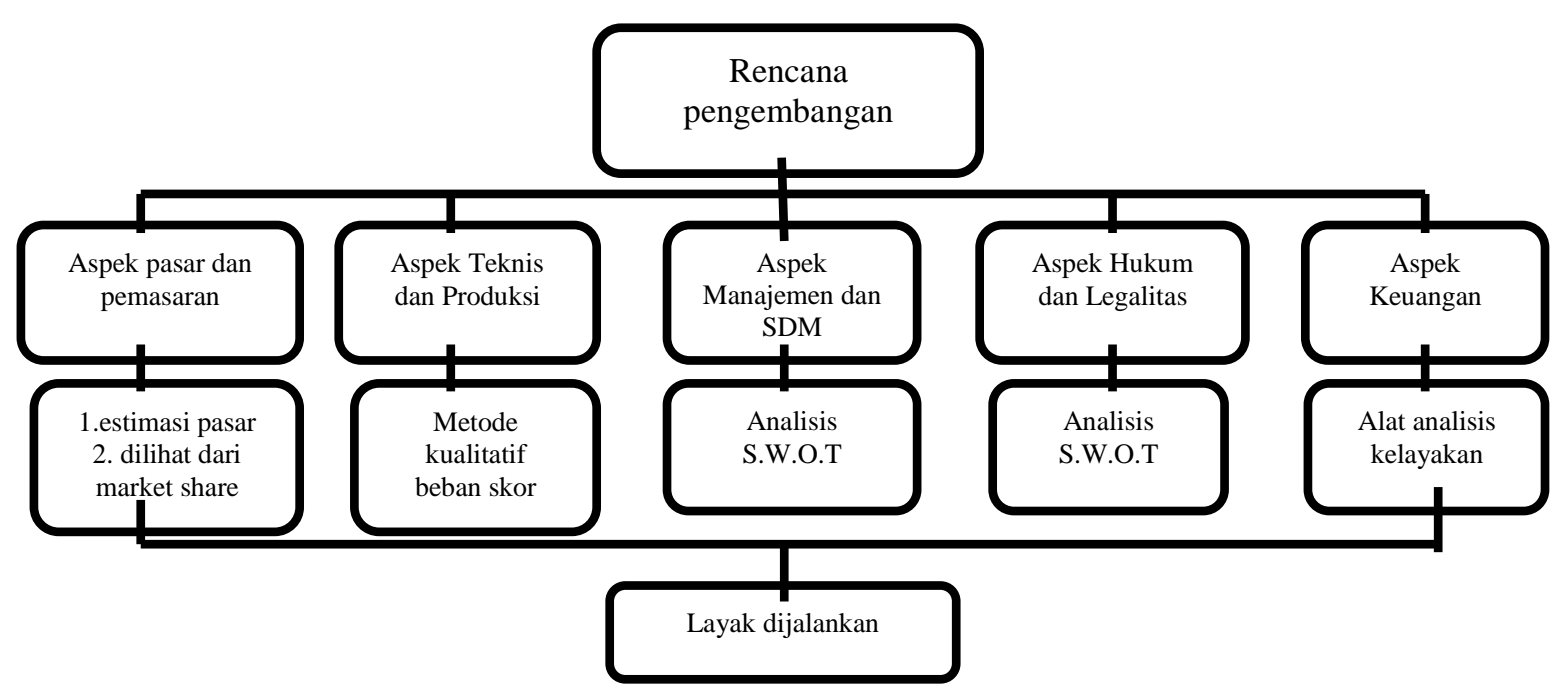

Gambar 1.1 Kerangka Pemikiran

\section{Hipotesis}

Berdasarkan permasalahan dan teori-teori yang telah dikemukakan di sub bab sebelumnya, maka penelitian ini mengambil hipotesis sebagai berikut:

H1 : Berdasarkan aspek pasar dan pemasaran ARTOMORO2 Mart layak untuk didirikan

H2 : Berdasarkan aspek Teknis Produksi dan Teknologi ARTOMORO2 Mart layak untuk didirikan

H3 : Berdasarkan aspek Manajemen dan Sumber Daya Manusia ARTOMORO2 Mart layak untuk didirikan

H4 : Berdasarkan aspek keuangan dan ekonomi ARTOMORO2 Mart layak untuk didirikan

H5 : Berdasarkan aspek hukum dan legalitas ARTOMORO2 Mart layak didirikan

\section{METODE PENELITIAN}

\section{Jenis Penelitian}

Jenis penelitian ini menurut metode adalah penelitian Ex Post Facto artinya adalah suatu penelitian yang dilakukan untuk meneliti peristiwa yang telah terjadi dan kemudian merunut ke belakang untuk mengetahui faktor-faktor yang dapat menimbulkan kejadian tersebut. Sedangkan menurut analisis datanya yaitupeneilitian kuantitatif(angka) berupa biaya investasi untuk asset tetap,biaya tetap,biaya variabel serta biaya lainnya dan data kualitatif berupa keterangan,informasi penjelasan,pendapat dan tanggapan dari pemilik . (Sugiyono1999:7)

\section{Objek Penelitian}

Objek penelitian ini adalah Analisis Kelayakan Investasi Pengembangan Usaha Artomoro2 Mart

\section{Data/Variabel Yang Digunakan}

Data yang digunakan penulis untuk mendapatkan informasi yang lebih akurat, yaitu data sekunder dan juga data primer. Data sekunder yakni data perkiraan pendapatan,tingkat suku bunga,perkiraan biaya-biaya,biaya izin usaha dan data investasi yang diperlukan. Sedangkan data primer yaitu sumber data diperoleh secara langsung dari sumber asli. 


\section{Metode Pengumpulan Data}

Metode pengumpulan data pada penelitian ini menggunakan penelitian survey, yaitu dengan terjun langsung kelapangan dan mengumpulkan data.

1. Riset Lapangan (Field Research)

Dalam hal ini penulis melakukan penelitian langsung ditempat atau objek yang dipilih yaitu ARTOMORO 2 Mart yang berlokasi Jl.Gunung Nangka ,Gentasari Cilacap. Dengan maksud untuk mendapatkan data yang akurat dengan mengadakan pengamatan langsung terhadap hal-hal yang berhubungan dengan penulisan ilmiah ini. Adapun cara yang digunakan dalam riset lapangan adalah:( Indriantoro:1999)

a. Observasi, yaitu mengadakan pengamatan secara langsung pada kegiatan objek dan proses manajemen pada ARTOMORO 2 Mart.

b. Wawancara, yaitu pengumpulan data dan informasi dengan cara berkomunikasi langsung dengan Bapak Jasimun Marosiswoyo selaku pemilik ARTOMORO 2 Mart dan Mas Sugeng selaku pengelola ARTOMORO 2 Mart.

\section{Metode Analisis Data}

Penelitian ini menurut analisis datanya termasuk penelitian kuantitatif berupa data yang berbentuk angka dan juga analisis deskriptif yaitu suatu metode analisis dimana data yang dikumpulkan mula-mula disusun, di klasifikasikan dan dianalisis sehingga akan memberikan gambaran yang jelas mengenai perusahaan dan masalah yang diteliti.(Sugiyono:1999)

1. Analisis aspek-aspek Studi Kelayakan Bisnis

a) Aspek pasar dan pemasaran,dianalisa dengan metode kuantitatif yaitu market share untuk menentukan pangsa pasar, metode least square untuk meramal permintaan.

b) Aspek Teknis Produksi dan Teknologis, dianalisa dengan metode metode kualitatif beban skor untuk menetukan lokasi produksi.

c) Aspek Sumber Daya Manusia dianalisa dengan metode kualitatif menggunakan analisis S.W.O.T mengenai struktur organisasi, job description, sistem kompensasi, program pengembangan karyawan, serta Sistem Informasi Manajemen (SIM) .

d) Aspek Hukum dan Legalitas, dianalisa dengan metode kualitatif dengan menggunakan analisis S.W.O.Tmembahas mengenai badan hukum organisasi dan jenis-jenis perizinan yang diperlukan.

e) Aspek Keuangan membahas mengenai penyusunan modal kerja dan modal investasi

\section{Definisi Operasional}

\section{Aspek pasar dan pemasaran}

Peramalan merupakan pengetahuan dan seni untuk memperkirakan apa yang akan terjadi di masa yang akan datang pada saat sekarang. Peramal harus mencari data dan informasi masa lalu. Data dan informasi masa lalu merupakan perilaku yang terjadi di masa lalu dengan berbagai kondisi pada saat itu.

Kondisi yang menyebabkan perilaku data dan informasi tersebut bisa dijadikan acuan bagi kondisi sekarang dan di masa yang akan datang. Hal ini perlu dilakukan mengingat di masa yang akan datang penuh dengan ketidakpastian.

Untuk melakukan peramalan permintaan di masa yang akan datang dapat dilakukan dengan salah satu cara sebagai berikut :

a) Metode leasquare

$\mathrm{Y}=\mathrm{a}+\mathrm{bx}$

$$
a=-\sum_{n} \quad b=-\sum^{----} \sum x
$$

b) Untuk menghitung bagian dari keseluruhan pasar potensial yang diharapkan dapat diserap oleh perusahaan digunakan metode market share (Gunawan Adisaputra, 1990).

Market share $=\underline{\text { Permintaan perusahaan }} \times 100 \%$

Permintaan industri 
Data permintaan perusahaan diambil dari data penjualan itu sendiri sedangkan data industri diambil dari data penjualan para pesaing.

2. Aspek Teknis Produksi dan Tekhnologi

Menurut Saud Husnan(1991) dalam aspek teknis atau produksi yang akan digambarkan secara lengkap adalah mengenai:

1. lokasi usaha, baik kantor pusat,cabang,pabrik atau gudang (penelitian mengenailokasi meliputi berbagai pertimbangan,apakah harus dekat dengan pasar, bahan baku, tenaga kerja,pemerintahan,lembaga keuangan,atau pertimbangan lainnya.

a) Metode Kualitatif atau Beban Skor

Salah satu metode yang dapat digunakan dalam dalam pengambilan keputusan pada lokasi mana proyek hendak didirikan yaitu Metode Kualitatif atau Beban Skor adalah metode dengan memberikan beban skor pada variabel utama maupun variabel bukan utama. Penggolongan tersebut sesuai dengan tingkat urgensi yang ditetapkan oleh perusahaan. Masing-masing perusahaan mempunyai kebijakan yang berbeda dalam menentukan urgensitas masing-masing variabel.

3.Aspek Manajemen dan Sumber Daya Manusia 2005)

Dalam aspek manajemen dan Sumber Daya Manusia yang harus dinilai (Husein Umar, a.Pemilik usaha (jumlah dan komposisi modal)

b.Pengolahan usaha (manajemen) dengan jumlah serta kualifikasi pendidikan yang berpengalaman

c.Struktur organisasi yg ada sekarang,gambaran mengenai jabatan rencana kerja seperti target,sasaran dan tujuan.

Informasi yang digunakan untuk menilai performance pribadi tersebut biasanya bersumber dari sesama pengusaha, media masa, perbankan, dll.

a) Metode analisis S.W.O.T

Analisis SWOT adalah salah satu teknik analisis untuk mengkaji Proses Bisnis dalam suatu Organisasi secara keseluruhan.Untuk mengkaji suatu organisasi perlu dilakukan analisis dengan melihat faktor internal (yang muncul dari dalam) dan faktor eksternal (yang ada atau datang dari luar).( Albert Humphrey, 1970)

Faktor-faktor internal yang dapat dianalisis yaitu:

1.Kekuatan(Strenghts)

2.Kelemahan(Weaknesses)

Sedangkan faktor-faktor eksternal, yaitu:

1.Peluang (Opportunities)

2.Ancaman (Threats)

\section{Aspek Keuangan}

Dalam aspek keuangan hal-hal yang perlu digambarkan adalah jumlah investasi,biayabiaya, dan pendapatan yang diperoleh. Besarnya investasi,jumlah dana yang akan dibutuhkan,baik untuk modal investasi,pembelian aktiva tetap maupun modal kerja. Selain itu, juga biaya-biaya yang diperlukan selama umur investasi dan pendapatan. Menilai jumlah kebutuhan investasi dan pembuatan cash flow. Setelah itu baru dinilai kelayakan usaha melalui metode penilaian investasi. Metode penelitian yang digunakanPayback Period, Average Rage of Return,Net Present Value,Internal Rate of Return,Profitability Indeks.

\section{a. Metode PP (Payback Period)}

Metode payback period (PP) merupakan teknik penilaian terhadap jangka waktu (periode) pengembalian investasi suatu royek atau usaha.

kriteria penilaian pada payback period adalah:

Payback periode $=\underline{\text { Jumlah investasi }} \times 12$ bulan

Kriteria penerimaan: Aliran kas bersih

Diterima jika $<5$ tahun

Ditolak jika $\geq 5$ tahun 


\section{b. Metode NPV (Net Present Value)}

Merupakan metode analisis keuangan yang memperhatikan adanya perubahan nilai uang karena faktor waktu; proyeksi arus kas data dinilai sekarang (periode awal investasi) melalui pemotongan nilai dengan faktor pengurang yang dikaitkan dengan biaya modal(prosentase bunga).

NPV $=$ Total PV = Aliran Kas Bersih - Total PV Investasis

Kriteria penerimaan:

Diterima jika bernilai positif

Ditolak jika bernilai negatif

\section{c. Metode IRR(Internal Rate of Return)}

IRR adalah tingkat bunga yang akan diterima (PV Future Procceds) sama dengan jumlah nilai sekarang dari pengeluaran modal (PV Capital Outlays).

$\mathrm{IRR}=\mathrm{PIM}-\mathrm{CI} \times \underline{\mathrm{P} 2}-\mathrm{PI}$

Keterangan :

$$
\mathrm{C} 2-\mathrm{C} 1
$$

P1 =Tingkat bunga 1

P2 = Tingkat bunga 2

$\mathrm{C} 1=\mathrm{NPV} 1$

$\mathrm{C} 2=\mathrm{NPV} 2$

Kriteria penerimaan:

Diterima jika > suku bunga pinjaman kredit ritel

Ditolak jika $\leq$ suku bunga pinjaman kredit ritel

\section{d. Metode PI ( Profitability Indeks)}

Indeks profitability adalah rasio atau perbandingan antara jumlah nilai sekarang arus kas selama umur ekonomisnya dan pengeluaran awal proyek.

PI = Total PV Kas Bersih

Total Investasi

Kriteria penerimaan:

Diterima jika $>1$

Ditolak jika $\leq 1$

\section{Aspek Hukum dan Legalitas}

Dalam aspek ini yang akan dibahas adalah masalah kelengkapan dan keabsahan dokumen perusahaan, mulai dari bentuk badan usaha sampai surat izin-izin yang dimiliki. Kelengkapan dan keabsahan dokumen sangat penting karena hal ini merupakan dasar hukum yang harus dipegang apabila di kemudian hari timbulmasalah. Keabsahan dan kesempurnaan dokumen dapat diperoleh dari pihak-pihak yang akan menerbitkan atau mengeluarkan dokumen tersebut.

Dokumen yang diperlukan meliputi:

a. Bentuk badan usaha serta keabsahannya dan untuk badan usaha tertentu, seperti perseroan terbatas atau yayasan harus disahkan oleh departemen kehakiman.

b. Tanda daftar perusahaan

c. Nomor pokok wajib pajak (NPWP)

Disamping dokumen diatas, perusahaan juga harus memmiliki izin-izin tertentu sesuai dengan jenis bidang usaha perusahaan izin-izin tersebut salah satunya surat izin perdagangan

1) Metode analisis S.W.O.T

Analisis S.W.O.T digunakan penelitian ini dalam menentukan kelayakan dari aspek hukum dan legalitas.Analisis S.W.O.Tadalah metode perencanaan srategis yang digunakan untuk mengevaluasi kekuatan (strengths), kelemahan (weaknesses), peluang (opportunities), dan ancaman (threats) dalam suatu proyek atau suatu spekulasi bisnis. Keempat faktor itulah yang membentuk akronim SWOT (strengths, weaknesses, opportunities, dan threats). Proses ini melibatkan penentuan tujuan yang spesifik dari spekulasi bisnis atau proyek dan mengidentifikasi faktor internal dan 
eksternal yang mendukung dan yang tidak dalam mencapai tujuan tersebut.( Albert

Humphrey, 1970)

\section{I11 HASIL PENELITIAN DAN PEMBAHASAN}

\section{Hipotesis pertama}

\section{Metode Market Share}

Untuk menghitung dengan metode market share digunakan rumus:

market share = permintaan perusahaanx $100 \%$

permintaan perusahaan + pesaing

Berdasarkan surveidiketahui bahwa data permintaan perusahaan diambil dari data penjualan minimarket sebesar dan data permintaan adalah data penjualan dari pesaing. Pesaing disini adalah alfamart dan dua toko sembako disekitarnya yang disajikan dalam table berikut:

Tabel 3.1 PerhitunganMetode Market Share

\begin{tabular}{|c|c|r|r|r|r|}
\hline No. & Tahun & \multicolumn{1}{|c|}{$\begin{array}{c}\text { Penjualan } \\
\text { (dalam juta rupiah) }\end{array}$} & \multicolumn{1}{c|}{$\begin{array}{c}\text { Penjualan } \\
\text { Pesaing }\end{array}$} & \multicolumn{1}{c|}{$\begin{array}{c}\text { Total } \\
\text { Penjualan }\end{array}$} & \multicolumn{1}{c|}{$\begin{array}{c}\text { Sarket } \\
\text { Share }(\%)\end{array}$} \\
\hline 1 & 2009 & 1008 & 1840 & 2848 & 35.39 \\
\hline 2 & 2010 & 1116 & 2050 & 3166 & 35.25 \\
\hline 3 & 2011 & 1242 & 2560 & 3802 & 32.67 \\
\hline 4 & 2012 & 1332 & 2450 & 3782 & 35.22 \\
\hline 5 & 2013 & 1458 & 2940 & 4398 & 33.15 \\
\hline
\end{tabular}

Sumber: Data diolah, 2015

Hal ini menunjukkan bahwa rata-rata pasar potensial yang dapat diserap oleh Artomoro 2 sebesar 34,34\% pada tahun 2013. Penyerapan pasar selama lima tahun terakhir menunjukkan peningkatan.

Berdasarkan analisis tersebut diketahui bahwa hipotesis pertama yang menyatakan berdasarkan aspek pasar dan pemasaran ARTOMORO2 Mart layak untuk didirikan, diterima.

Dalam pendirian sebuah toko aspek pasar dan pemasaran sangat penting karena dari aspek ini kita dapat melihat peluang usaha serta serapan pasar dari usaha kita. Kita juga memperhitungkan pesaing agar tetap bisa bersaing dengan sehat.

\section{Hipotesis kedua}

Menyatakan berdasarkan aspek Teknis Produksi dan Teknologi ARTOMORO2 Mart layak untuk didirikan, diterima.Hal ini karena ARTOMORO2 Mart telah menerapkan teknologi yang maju, walaupun tidak memproduksi barang karena hanya bergerak dalam bidang perdagangan.

Tabel 3.2 Perhitungan Beban Skor Tiap Lokasi

\begin{tabular}{|l|c|c|c|c|c|c|c|}
\hline \multirow{2}{*}{ Faktor yang dinilai } & \multirow{2}{*}{ Bobot } & \multicolumn{3}{|c|}{ Lokasi Potensial } & \multicolumn{3}{c|}{ Bobot X Skor } \\
\cline { 3 - 8 } & & Duku & $\begin{array}{c}\text { Sidasari } \\
\text { (Kroya) }\end{array}$ & $\begin{array}{c}\text { Karang } \\
\text { asem }\end{array}$ & $\begin{array}{c}\text { Gunung } \\
\text { nangka }\end{array}$ & $\begin{array}{c}\text { Sidasari } \\
\text { (Kroya) }\end{array}$ & $\begin{array}{c}\text { Karang } \\
\text { asem }\end{array}$ \\
\hline Lokasi & 40 & 2 & 4 & 2 & 80 & 160 & 80 \\
\hline Transportasi & 30 & 2 & 4 & 3 & 60 & 120 & 90 \\
\hline $\begin{array}{l}\text { Sumber energi atau } \\
\text { tenaga listrik }\end{array}$ & 10 & 4 & 4 & 3 & 40 & 40 & 30 \\
\hline Tingkat upah & 20 & 4 & 3 & 4 & 80 & 60 & 80 \\
\hline \multicolumn{3}{|c|}{ Jumlah beban skor } \\
\hline
\end{tabular}

Sumber: Data diolah, 2015 
Dari hasil analisis tersebut diketahui bahwa lokasi yang memiliki nilai beban skor tertinggi adalah Sidasari Kroya.Sehingga lokasi tersebut paling tepat untuk dijadikan pembangunan Artomoromart 2.

Berdasarkan uraian tersebut maka hipotesis kedua yang menyatakan berdasarkan aspek Teknis Produksi dan Teknologi ARTOMORO2 Mart layak untuk didirikan, diterima.

\section{Hipotesis ketiga}

Menyatakan berdasarkan aspek Manajemen dan Sumber Daya Manusia ARTOMORO2 Mart layak untuk didirikan, diterima. Hal ini karena sumberdaya manusia yang ada sudah sesuai dengan kebutuhan. Dan memiliki manajemen yang cukup jelas.

Berdasarkan Analisis SWOT ARTOMORO2 memiliki kekuatan antara lain karyawan memiliki pendidikan yang sesuai, penerimaan karyawan dilakukan secara ketat dan pelayanan ramah dalam melayani karyawan.Serta memiliki peluang karena banyak calon tenaga kerja yang tersedia disekitar lokasi Artomoro 2.Dan memiliki manajemen yang baik maka peluang untuk berhasilnya lebih tinggi.

Dalam menjalankan sebuah usaha memerlukan manajemen yang baik agar usaha dapat berjalan dengan lancar. Manajemen yang baik didukung dengan sumber daya manusia yang berkualitas dan sesuai dengan keahliannya.

\section{Hipotesis keempat}

Berdasarkan aspek keuangan dan ekonomi ARTOMORO2 Mart layak untuk didirikan, diterima.Hal ini karena berdasarkan perhitungan aspek keuangan semua menunjukkan bahwa investasi layak untuk dilakukan.

Tabel 3.3 Rekapitulasi Aspek Keuangan

\begin{tabular}{|l|r|l|}
\hline \multicolumn{1}{|c|}{ Metode } & \multicolumn{1}{c|}{ Hasil } & \multicolumn{1}{c|}{ Kesimpulan } \\
\hline Payback Periode & 3,5 tahun & Diterima karena $<5$ tahun \\
\hline Net Present Value & Rp 845.076.016 & Diterima karena bernilai positif \\
\hline Internal Rate of Return & $15,63 \%$ & $\begin{array}{l}\text { Diterima karena }>\text { suku bunga } \\
\text { pinjaman kredit ritel }(12,50 \%)\end{array}$ \\
\hline Profitability Indeks & 2,5 & Diterima $>1$ \\
\hline
\end{tabular}

Dalam menjalankan usaha harus memperhatikan aspek keuangan dan ekonomi. Dengan perhitungan keuangan yang baik maka usaha dapat berjalan dengan baik. Karena usaha yang didirikan berhubungan dengan perdagangan yang berhubungan erat dengan aspek keuangan.

\section{Hipotesis kelima}

Berdasarkan aspek ARTOMORO2 Mart layak Hukum dan Legalitas, diterima.Hal ini karenaARTOMORO2 Mart memiliki beberapa kekuatan antara lain sudah memiliki NPWP, memiliki bukti KTP dan SIM, memiliki sertifikat tanah, memiliki surat ijin usaha dan memiliki sertifikat lainnya.

Dalam mendirikan usaha aspek hukum dan legalitas sangat penting. Dengan memiliki legalitas yang jelas maka akan lebih mudah memperoleh pinjaman dari bank untuk memperbesar usaha.

\section{PEMBAHASAN}

Berdasarkan penjelasan tersebut maka ARTOMORO2 Mart layak untuk didirikan karena dari kelima aspek yang dianalisis semuanya diterima. Sehingga pendirian ARTOMORO2 Mart dapat segera dilakukan. 


\section{KESIMPULAN DAN SARAN}

Kesimpulan

1. Hipotesis pertama yang menyatakan berdasarkan aspek pasar dan pemasaran ARTOMORO2 Mart layak untuk didirikan, diterima. Hal ini karena dari aspek pasar dan pemasaranARTOMORO2 Mart telah baik dengan strategi yang kompetitif.

2. 2.Hipotesis kedua yang menyatakan berdasarkan aspek Teknis Produksi dan Teknologi ARTOMORO2 Mart layak untuk didirikan, diterima.Hal ini karena ARTOMORO2 Mart telah menerapkan teknologi yang maju, walaupun tidak memproduksi barang karena hanya bergerak dalam bidang perdagangan.s

3. Hipotesis yang menyatakan berdasarkan aspek keuangan dan ekonomi ARTOMORO2 Mart layak untuk didirikan, diterima. Hal ini karena berdasarkan perhitungan aspek keuangan semua menunjukkan bahwa investasi layak untuk dilakukan.

4. Hipotesis yang menyatkan berdasarkan aspek ARTOMORO2 Mart layak Hukum dan Legalitas, diterima. Hal ini dikarenakan ARTOMORO2 mart sudah memiliki SIUP (Surat Ijin Usaha)

5. ARTOMORO2 Mart layak untuk didirikan karena dari kelima aspek yang dianalisis semuanya diterima dan investasi dapat segera dilaksanakan.

\section{Saran}

Berdasarkan kesimpulan tersebut diatas dan sebagai bahan pertimbangan, maka penulis dapat memberikan saran hendaknya ARTOMOTO mart2 meningkatkan gaji karyawan karena masih tergolong kecil yaitu 500.000 dan belum sesuai dengan UMR (Upah Minimum Regional) di Cilacap 986.000 (berdasarkan situs indoline_indonesia.com).

\section{Keterbatasan Penelitian}

Dalam penelitian masih terdapat banyak keterbatasan penelitian yang dapat mempengaruhi hasil penelitian, yaitu:

1. Peneliti hanya membatasi dengan 5 aspek saja dan masih ada aspek yang belum diteliti agar pendirian usaha berjalan dengan lancar

2. Dalam aspek pasar dan pemasaran hanya 3 pesaing yang menjadi peneliti yaitu alfamart dan 2 toko sembako lain ada pesaing lain yang belum diteliti agar dapat mengetahui marketshare diwilayah tersebut.

\section{DAFTAR PUSTAKA}

Abdul Halim. 2005. Analisis Investasi. Salemba Empat, Jakarta.

Gunawan Adisaputro. 1990. Anggaran Perusahaan II, BPFE,UGM, Yogyakarta.

Humphrey,Albert. 2005. SWOT Analysis for Management Consulting. SRI Alumni Newsletter (SRI International)

Husein Umar. 2005. Studi Kelayakan Bisnis, Edisi 3. PT Gramedia Pustaka Utama, Jakarta.

Indriantoro.1990. Manajemen Keuangan. BPFE,UGM, Yogyakarta.

Kasmir dan Jakfar.2007. “Study Kelayakan Bisnis”. Rhineka Cipta. Yogyakarta

Kotler, Philip.2005. Manajemen Pemasaran, Jilid 2, Edisi 11. Indeks, Jakarta

Murdifin dan Salim. 2010. Studi Kelayakan Investasi dan Bisnis. PT Bumi Aksara, Jakarta. 
Rahardjo, Budi. 2005. "Laporan Keuangan Perusahaan. Membaca, memahami dan Menganalisis”. Gadjah Mada University Press. Yogyakarta.

Saud Husnan, Suwarsono. 1991. Studi Kelayakan Proyek. Unit penerbit percetakan AMP YKPN.

Situs indoline_indonesia.com.

Sugiyono. 1999. Metode Penelitian Bisnis. Alfabeta, CV. Bandung. 